\section{SANDIA REPORT}

\section{SAND99-0173}

Unlimited Release

Printed February 1999
HS- $\theta 619$-RevIew \& Approval-Degk, 15102

For DeE/OSTL.
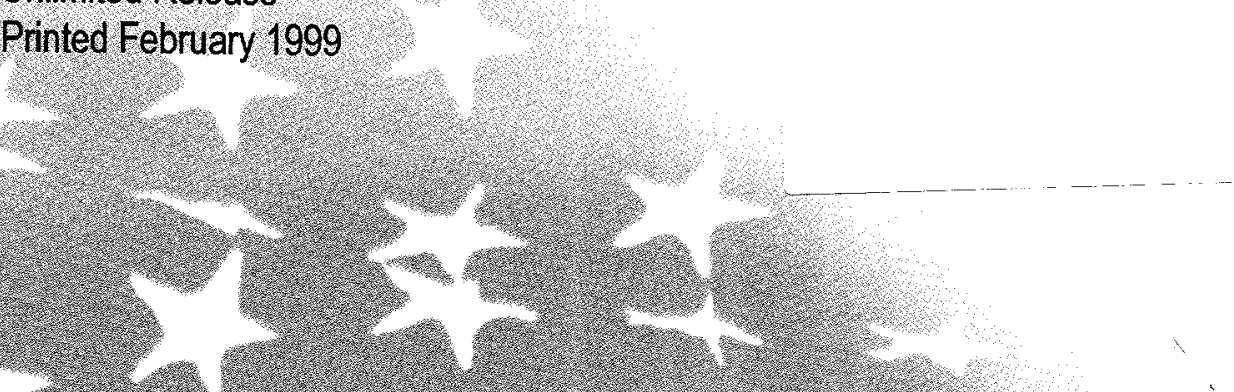

RECFIVFD FEB 18 :

os I.

\title{
Automated Geometric Model Builder Using Range Image Sensor Data: Final Acquisition
}

Carl Diegert and John Sackos

Prepared by

Sandia National Laboratories

Albuquerque, New Mexico 87185 and Livermore, California 94550

Sandia is a multiprogram laboratory operated by Sandia Corporation, a Lockheed Martin Company for the United States Department of

Energy under Contract DE AC0494AL85000.

Approved for public release, further dissemination unlimited.

\section{Sandia National Laboratories}


Issued by Sandia National Laboratories, operated for the United States Department of Energy by Sandia Corporation.

NOTICE: This report was prepared as an account of work sponsored by an agency of the United States Government. Neither the United States Government nor any agency thereof, nor any of their employees, nor any of their contractors, subcontractors, or their employees, makes any warranty, express or implied, or assumes any legal liability or responsibility for the accuracy, completeness, or usefulness of any information, apparatus, product, or process disclosed, or represents that its use would not infringe privately owned rights. Reference herein to any specific commercial product, process, or service by trade name, trademark, manufacturer, or otherwise, does not necessarily constitute or imply its endorsement, recommendation, or favoring by the United States Government, any agency thereof, or any of their contractors or subcontractors. The views and opinions expressed herein do not necessarily state or reflect those of the United States Government, any agency thereof, or any of their contractors.

Printed in the United States of America. This report has been reproduced directly from the best available copy.

Available to DOE and DOE contractors from

Office of Scientific and Technical Information

P.O. Box 62

Oak Ridge, TN 37831

Prices available from (615) 576-8401, FTS 626-8401

Available to the public from

National Technical Information Service

U.S. Department of Commerce

5285 Port Royal Rd

Springfield, VA 22161

NTIS price codes

Printed copy: A11

Microfiche copy: A01

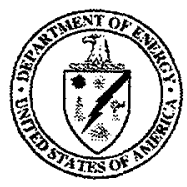




\section{DISCLAIMER}

Portions of this document may be illegible in electronic image products. Images are produced from the best available original document. 


\title{
Automated Geometric Model Builder Using Range Image Sensor Data: Final Acquisition
}

\author{
Carl Diegert \\ Computer Architectures Department \\ Sandia National Laboratories \\ P.O. Box 5800 \\ Albuquerque, NM 87185-1109 \\ diegert@,cs.sandia.gov \\ John Sackos \\ Firing Set \& Mechanical Design \\ Sandia National Laboratories \\ P.O. Box 5800 \\ Albuquerque, NM 87185-1109 \\ jtsacko@sandia.gov
}

\begin{abstract}
This report documents a data collection where we recorded redundant range image data from multiple views of a simple scene, and recorded accurate survey measurements of the same scene. Collecting these data was a focus of the research project, Automated Geometric Model Builder Using Range Image Sensor Data (96-0384), supported by Sandia's Laboratory-Directed Research and Development (LDRD) Program during fiscal years 1996, 1997, and 1998. The data described here are available from the authors on CDROM, or electronically over the Internet. Included in this data distribution are Computer-Aided Design (CAD) models we constructed from the survey measurements. The CAD models are compatible with the SolidWorks 98 Plus system, the modern Computer-Aided Design software system that is central to Sandia's DeskTop Engineering Project (DTEP). Integration of our measurements (as built) with the constructive geometry process of the $\mathrm{CAD}$ system (as designed) delivers on a vision of the research project. This report on our final data collection will also serve as a final report on the project.
\end{abstract}




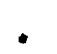

Intentionally Left Blank 


\section{Table of Contents}

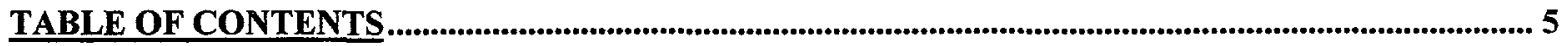

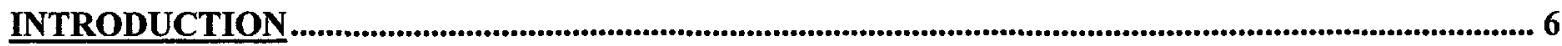

TEST SCENE

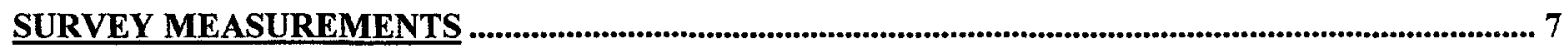

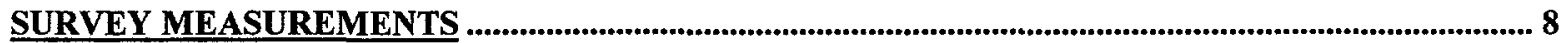

CAD MODELS FROM SURVEY MEASUREMENTS _............................................................................. 11

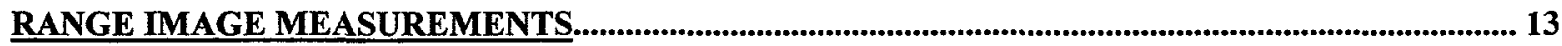

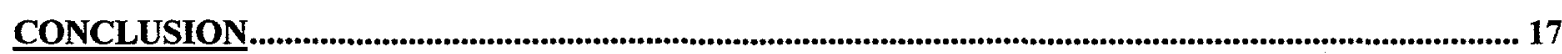

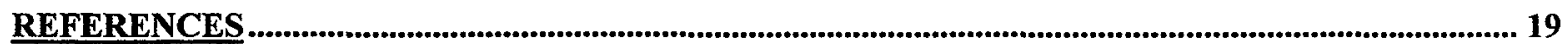




\section{Introduction}

Light radar instruments (LADAR) constructed using flood illumination, and using an imaging receiver can inexpensively produce abundant information on the shapes of visible surfaces in a scene. By recording range images of a static scene from multiple viewpoints, we can record redundant information on the shape and location of the scene's surfaces. By statistically reducing these data, we may be able to obtain a surface model with accuracy much greater than is possible when processing a single, best range image view of each surface. We may also be able to estimate surface shape and location from multiple views without the single-image biases from multipath ambiguities and other systematic error sources.

This report describes data we collected in support of experiments with building models from the redundant information in multiple range images. We recorded both range images from an experimental, flood-illuminated LADAR, and recorded survey measurements on the main surfaces in the scene. We have also used the survey measurements to build a model of the scene's major features using a Computer-Aided Design (CAD) software application called SolidWorks 98 Plus. The CAD environment is a powerful tool for easily computing and displaying new views and dimensions as needed when working with the range and survey measurements. We archived the CAD models, together with the survey and range image measurements to facilitate subsequent work.

\section{Test Scene}

We set up a simple scene, comprising two objects with approximately rectangular, planar faces, a planar floor, and a planar wall backdrop. We positioned the two objects, a wooden shipping box (box) and a fan coil cooler unit (cooler), so that they would occlude each other in the various range images we obtained. We set up the scene in a high bay area of Sandia's building 826. Figure 1 shows the scene, with box, cooler and wall positioned for the data collection. We acquired the survey and range image data on August 8, 1998. 


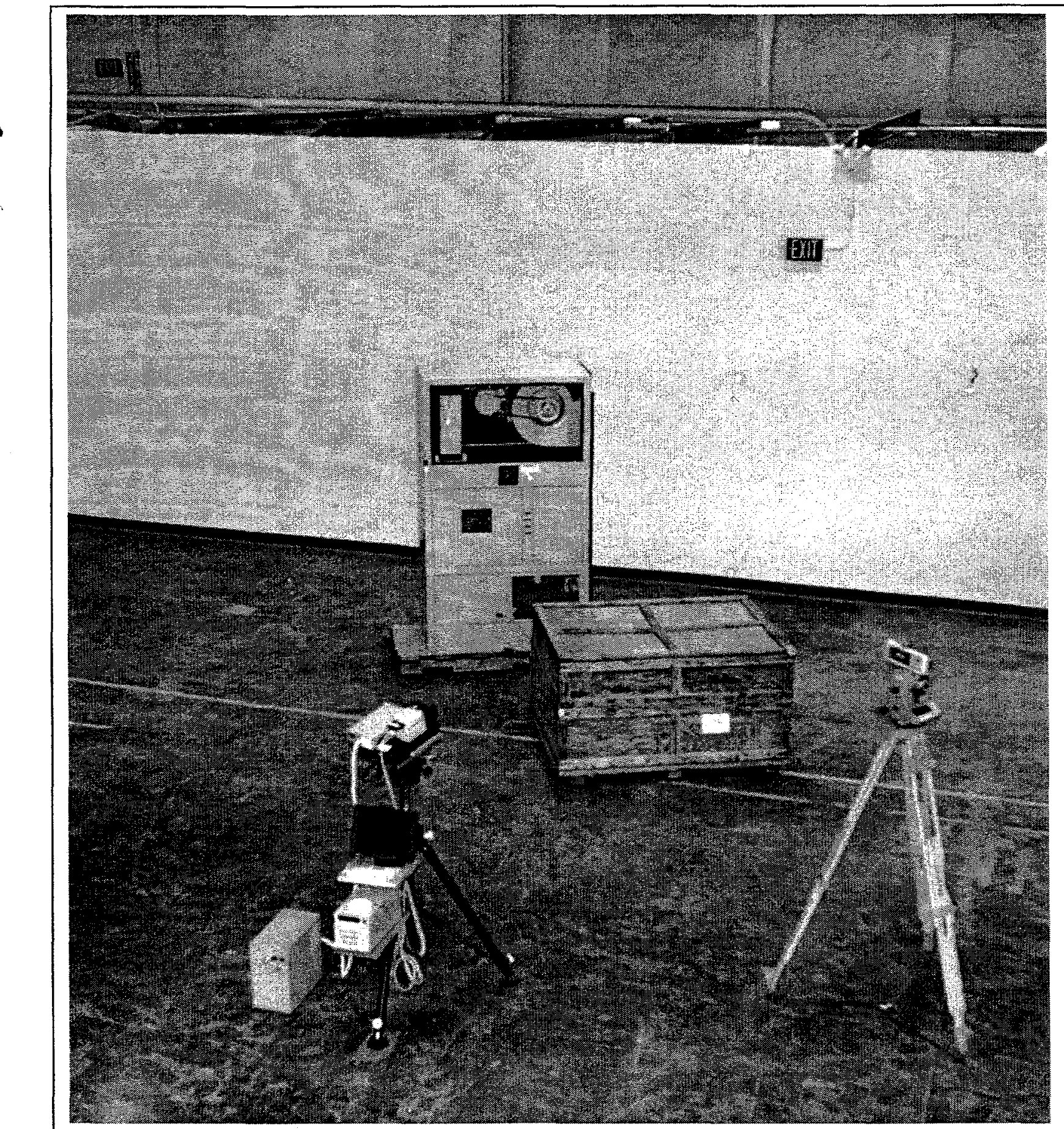

Figure 1. Simple scene comprising a box object, cooler object, wall, and floor. The left tripod supports Sandia's range image sensor located at data collection station 7 . The right tripod supports the Leica electronic theodolite and distancemeasuring instrument used to collect survey-quality ground truth. 


\section{Survey Measurements}

To obtain survey measurements, we occupied a station location with an electronic theodolite (Leica Model TM1800) equipped with a laser distance meter (Leica Power Disto), Leica bracket and software. This instrumentation allowed us to establish a coordinate system with coordinate origin on the floor directly under the theodolite station, and with three mutually orthogonal axes called elevation, northing, and easting. The leveling system in the modern theodolite establishes the elevation axis to within one arc second of true vertical. Sighting the number two target marker (the rightmost marker on the wall) through the theodolite telescope allowed us set establish the northing coordinate perpendicular to elevation, and with the plane formed by elevation and northing intersecting this wall target. The easting coordinate is, of course, taken perpendicular to the northing-elevation plane. The conservative accuracy specification for the Power Disto, plus-or-minus 5 millimeters, is large relative to other errors in the TM1800/Disto system.

File survey/shots . txt, included in our digital archive, gives coordinates of fifteen points in the scene as a comma-separated variable, text-format file. This information is also displayed in table 1 . The first line of the file (row of the table 1) defines point number 1 at coordinate $(0,0,0)$. This is the location of a marker on the floor directly under the theodolite. The next five lines of the file give coordinates of five targets arranged in a cross pattern on the wall behind the box and cooler. The next six lines are coordinates of six stations we sequentially occupied with our range-imaging instrument. We recorded these six station location coordinates at the point where the optical axis of the range-imaging instrument's receiver camera lens intersected its external (first) lens surface. The last four lines of the file are coordinates of target markers, two on the cooler front face, and two on the box front face.

We used a tape measure to record dimensions (in meters) of the wooden box: 1.50 wide, 1.12 deep, and 0.79 high, and of the cooler: 1.21 wide, 0.755 deep, and 2.80 high. Height of the box excludes the palette between the box and the floor. Distance from top of the box to the floor was 0.885 . Under the cooler was a palette with palette height 0.13 . We placed two target markers on the front face of the box at height 0.416 from its bottom. We placed two target markers on the front face of the cooler at height 1.88 from its bottom. 
Table 1. Coordinates of scene features and observation stations.

\begin{tabular}{|c|c|c|c|c|}
\hline & $\begin{array}{l}\text { Point } \\
\text { Label }\end{array}$ & $\begin{array}{l}\text { Easting } \\
\text { (meters) }\end{array}$ & $\begin{array}{l}\text { Northing } \\
\text { (meters) }\end{array}$ & $\begin{array}{l}\text { Elevation } \\
\text { (meters) }\end{array}$ \\
\hline Theodolite Station & 1 & 0 & 0 & 0 \\
\hline \multirow[t]{5}{*}{ Wall Target } & 2 & -0.001 & 6.479 & 1.849 \\
\hline & 3 & -1.904 & 6.541 & 1.850 \\
\hline & 4 & -3.810 & 6.596 & 1.851 \\
\hline & 5 & -1.907 & 6.549 & 0.146 \\
\hline & 6 & -1.907 & 6.534 & 3.559 \\
\hline \multirow[t]{6}{*}{ Range Image Station } & 7 & -2.090 & -0.455 & 1.133 \\
\hline & 8 & -2.772 & -3.393 & 1.655 \\
\hline & 9 & -6.610 & -2.383 & 1.694 \\
\hline & 10 & -8.689 & 0.360 & 1.678 \\
\hline & 11 & -9.888 & 5.756 & 1.693 \\
\hline & 12 & 4.112 & 0.517 & 1.666 \\
\hline \multirow[t]{2}{*}{ Cooler Target } & 13 & -3.730 & 3.857 & 2.086 \\
\hline & 14 & -2.624 & 4.343 & 2.083 \\
\hline \multirow[t]{2}{*}{ Box Target } & 15 & -2.214 & 2.018 & 0.755 \\
\hline & 16 & -0.855 & 2.658 & 0.747 \\
\hline
\end{tabular}




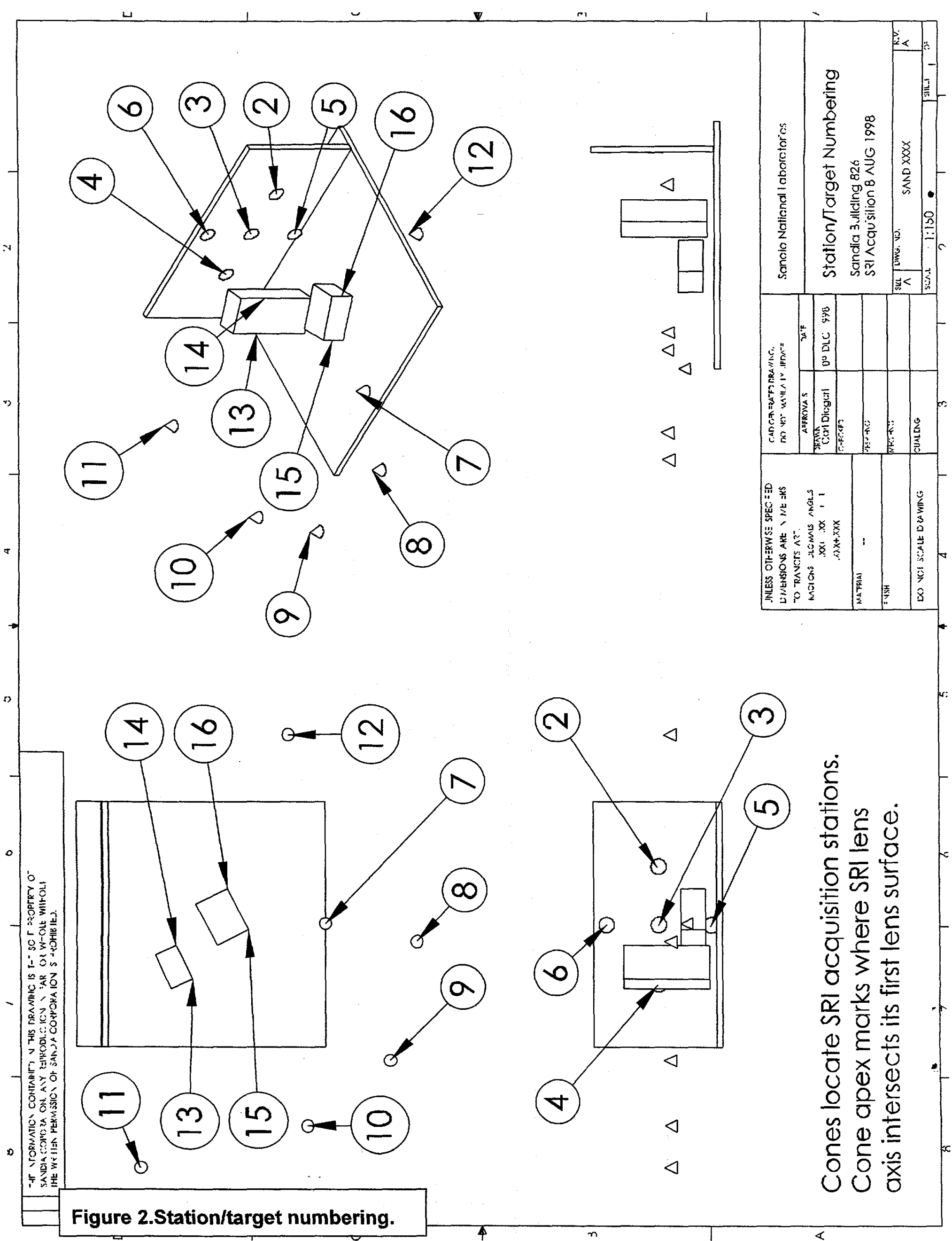


The TM1800 theodolite recorded the source information for these survey measurements in the Wild Geo Serial Interface (GSI) format [1]. These source data are in file survey/shots.gsi in the archive. At first, we used the Leica/Wild Survey Engineering Environment (SEE) software to work with these measurements. This software appears well suited for analysis of conventional land surveys, but was awkward for manipulating our scene measurements. We wrote a short program, gsi2csv, and used it in place of SEE to translate file shots.gsi file into a comma-separated variable text file shots.txt.

We implemented an optional $\% \mathrm{~s}$ flag argument in the gsi2Csv program to produce a series of files, each in comma-separated variable format, to load the coordinates into the SolidWorks 98 Plus system. For each point in the input, GSI-format file, the optional use of our gsi2 Csv program writes a separate text file. For an input point numbered, say, 13, at coordinate (easting, northing, elevation) $=(10,20,30)$, the program will write a file named line13. slderv. This file will comprise two lines, one to define a start point of $(0,0,0)$, and a second to define an end point of $(20,60,-40)$. In general, the first point is always $(0,0,0)$, and the second point's three coordinate values are: twice the input easting coordinate value, twice the input elevation value, and the negative of twice the northing coordinate. From SolidWorks, then, we can introduce the measured coordinate by adding a reference geometry entity called line through free points by referring to this file. The midpoint of this reference line is at the surveyed coordinate, given the SolidWorks conventions for front, top, and right views. The sldcrv files are in archive directory model.

\section{CAD Models from Survey Measurements}

The SolidWorks assembly defined in file model/room. sldasm places into correct geometric relationship the simple scene's floor (model/floor . sldprt), wall (model/wall.sldprt), cooler (model/cooler.sldprt), box (model/wood_box.sldprt), five wall targets (model/target-disc.sldprt), and six measurement stations (model/station. sldprt). Figure 2 shows four views of these elements, and also shows the numbering of the surveyed points. The floor is taken to be perfectly level, and intersecting the $(0,0,0)$ point below the theodolite. The wall is taken to be perfectly planar, although is it not quite perpendicular to the floor. The three orthogonal views that appear in Figure 2 are constructed from a coordinate system defined by the floor plant and the axis formed by the intersection of the floor plane and the wall plane. Note that this coordinate system is not quite coincident with that used to record the surveyed points in table 1 . The fourth view in figure 2 is isometric, and is formed from the same coordinate system that defines the other three views.

Figures 3,4 , and 5 show a few dimensions from the first three observation stations. All dimensions are in meters. The wall is planar to within measurement error, but is not quite perpendicular to level. The floor model is perfectly level, but may not correspond precisely to the actual floor. We placed the floor model at the $(0,0,0)$ coordinate below the theodolite measurement station (Station 1). 


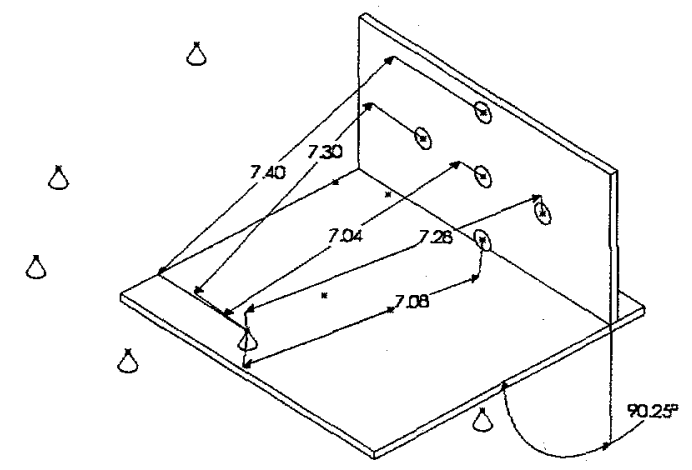

Figure 3. A few dimensions from Station 7.

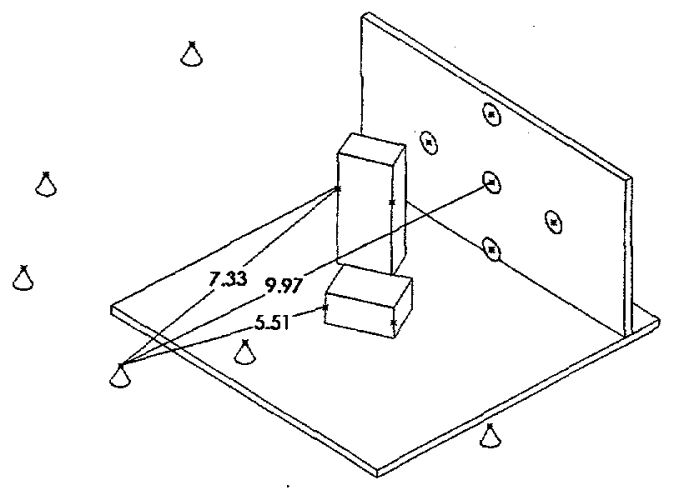

Figure 4. A few dimensions from Station 8. 


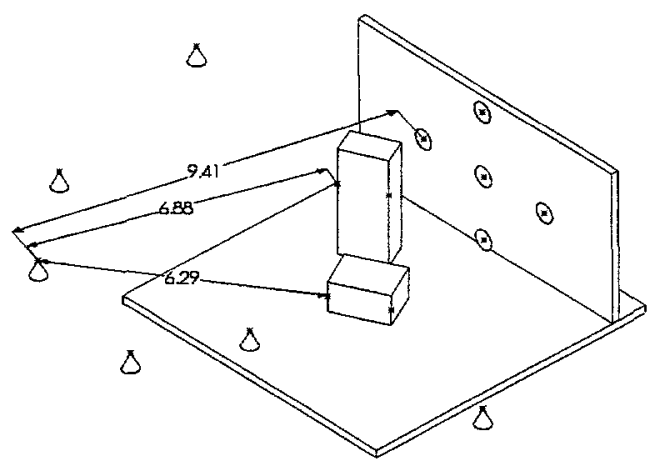

Figure 5. A few dimensions from Station 9.

\section{Range Image Measurements}

Sandia's Scannerless Range Imager (SRI) is a compact, low-cost, high-resolution, highframe rate, range imaging optical radar. This innovative technology provides a means for high-speed collection of range imagery over a large field of view (object plane) without the use of any type of beam steering (scanning). It is a floodlight illuminated, total field-of-view (staring) laser radar (LADAR) system that uses an intensity-modulated light-source transmitter, and an image intensified, charge coupled device (ICCD) video camera receiver.

From this patented technology [5], range (relative phase) information from the return of an amplitude-modulated scene illumination signal can be extracted from the pre-detection mixing of this signal with an injected local oscillator. This mixing occurs within the image intensifier, and the subsequent extraction of relative phase (the range) information can be demodulated using a conventional personal computer. Because the pre-detection mixing occurs simultaneously for each pixel across the entire imaged scene, the range information can be rapidly detected using a very simple receiver system.

Figure 6 shows an SRI instrument, as configured to collect the measurements described in this report. We collected all data in a high bay warehouse environment with overhead high intensity lights on. A computer running Microsoft's Windows 98 operating system, together with an operator's commands from its keyboard/mouse/display, controls the data acquisition. For the acquisition described here, the same computer saved the collected data to an integral disk drive. At the top of the tripod are two parallel optical systems: the receiver (closer to the viewer) and the flood illuminator.

For these measurements, the receiver was based on a grayscale video camera with 10-bit resolution (Kodak model 1.6i). This particular camera contains a CCD where 1532 pixels are 
in each horizontal row, and 1024 pixels are in each vertical column. The CCD was fiber optically coupled to a 18mm Litton (formerly, Varo) Generation III (GaAs) image intensifier to form an intensified charge coupled device (ICCD) assembly. A conventional video camera lens with $24 \mathrm{~mm}$ focal length, F/1.4 aperture, and c-mount imaged the scene onto this ICCD. The resulting imager had a spatial resolution of approximately 50 lines per millimeter.

The flood illuminator for this data collection was a pulsed, frequency doubled NdYAG laser (model Mini-light 10 from Continuum). It operated at the $532 \mathrm{~nm}$ (green) wavelength, and produced 15 nanosecond, 50 millijoule pulses at a $10 \mathrm{~Hz}$ pulse repetition rate. Modulation of the transmitter and synchronous receiver was at $10 \mathrm{MHz}$. No filter was used on the receiver, but an electronic shutter was set to open for a few hundred nanoseconds around each received pulse was, thus to limiting the collection of background light. We aligned the laser axis and diverged its beam to illuminate all but the extreme corners of the scene.

We used temporal averaging, averaging a conservatively large number (30) of sequentially obtained range images. This averaging reduced the adverse effects of uncorrelated noise on the measurement performance of the sensor. A quick, conservative analysis of range image data from this sensor shows a range resolution of ten centimeters.

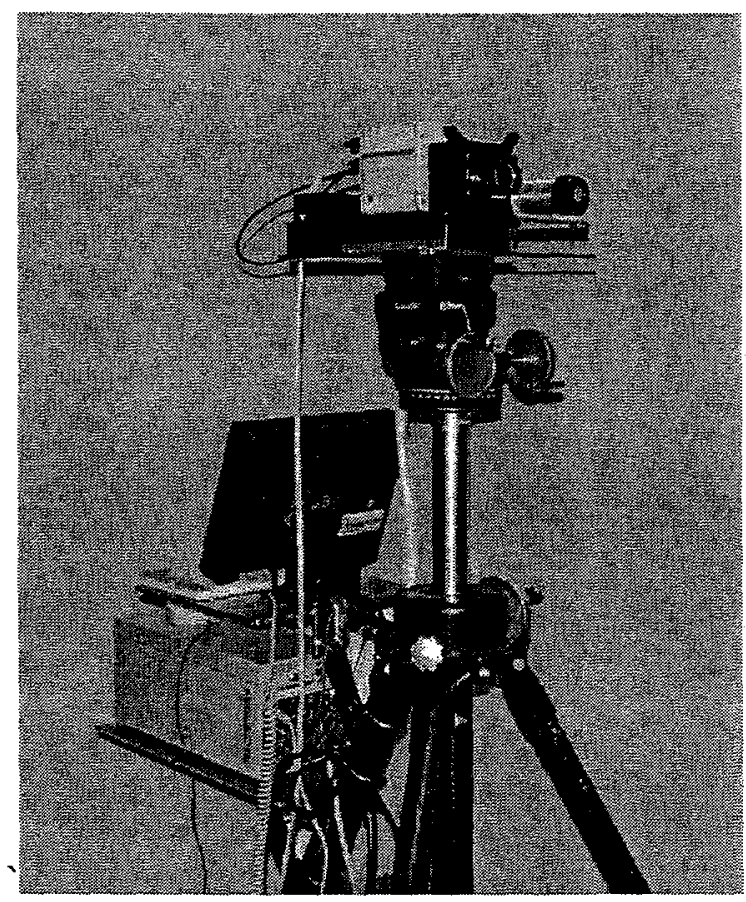

Figure 6. Range imaging instrument.

As a result of the $10 \mathrm{MHz}$ operating frequency, the SRI system measures 2.385 meters per radian (7.827 feet per radian or 93.924 inches per radian), or 0.419 radians per meter $(0.127$ radians per foot or 0.010 radians per inch). A range ambiguity occurs after a full ( $2 \mathrm{Pi}$ ) interval, corresponding to 14.9896 meters (49.178 feet). Since the variation in ranges to all objects in our scene was less than 15 meters, there are no range ambiguities in the recorded 
data. Further, because we did not power cycle or adjust the SRI during the complete data collection at all six stations, the range measurements have a common (but arbitrary) zero relative range (phase) reference. Accurate, redundant survey measurements on the flat wall surface (point labels 2, 3, 4, 5 and 6) can be used to obtain a precise estimate of the fixed range offset in the range images.

We transferred single images from this camera with an unsigned, 10 bit intensity for each pixel in this camera's 1532 by 1024 pixel array. The range imaging process demands multiple images, with some processing performed by the controlling computer. For these measurements, we averaged 30 sequential range image measurements to form a single range image archived to disk. Each of these component range images was formed from eight images with equally spaced phase offsets between the flood illuminator and the phasesensitive receiver. The scannerless range imaging process is described, for example, in [2]. The range image formation and the averaging is all computed using 32-bit, floating-point arithmetic. As part of forming the range images, we also form a reflectance image. The location of the flood illuminator parallel and to the left of the receiver is apparent in the shadow features in the reflectance images.

Our digital archive of the range and reflectance image information includes six pairs of images in a raw data format. In this format, the value of each pixel is a range expressed in radians and represented by four bytes in the file. The pixel value is represented in the IEEEstandard representation. The pixels appear in row-major order, and there is no header or other information in the file, and no compression. The number of bytes in each of these files, then, is four times their number of pixels, $(4)(1532)(1024)=6,272,072$ bytes. For our own work with these data, we store these images in tiff format, using both the little-used tiff standard for storing floating-point pixel values, and using a few of our own extensions to include various information into the file headers. We have not included these non-standard versions of the six pairs of images in the archive.

The raw-format reflectance and range images from Station 7 are in archive files sri/raw/CAL_7_REF.raw and sri/raw/CAL_7_RNG.raw, receptively. As is clear from the images, the box and cooler objects were not moved into the scene until after we acquired the Station 7 data.

The raw-format reflectance and range images from Station 8 are in archive files sri/raw/BOX 8 REF. raw and sri/raw/BOX 8 RNG.raw. The images from Stations $9,10,11$, and 12 , follow this naming, with the station number substituted for the digit 8 in the names.

Tables 2 and 3 show small, low-quality versions of the six range and reflectance images. To form lightweight reflectance images that most clearly depicted scene features, we interactively choose a window into the huge dynamic range inherent in the floating-point pixel values. We then downsampled the images to greatly reduce the number of pixels, and applied a filter to sharpen the image features. 
Table 2. Reflectance images from each of six measurement stations after downsampling and adjustments.

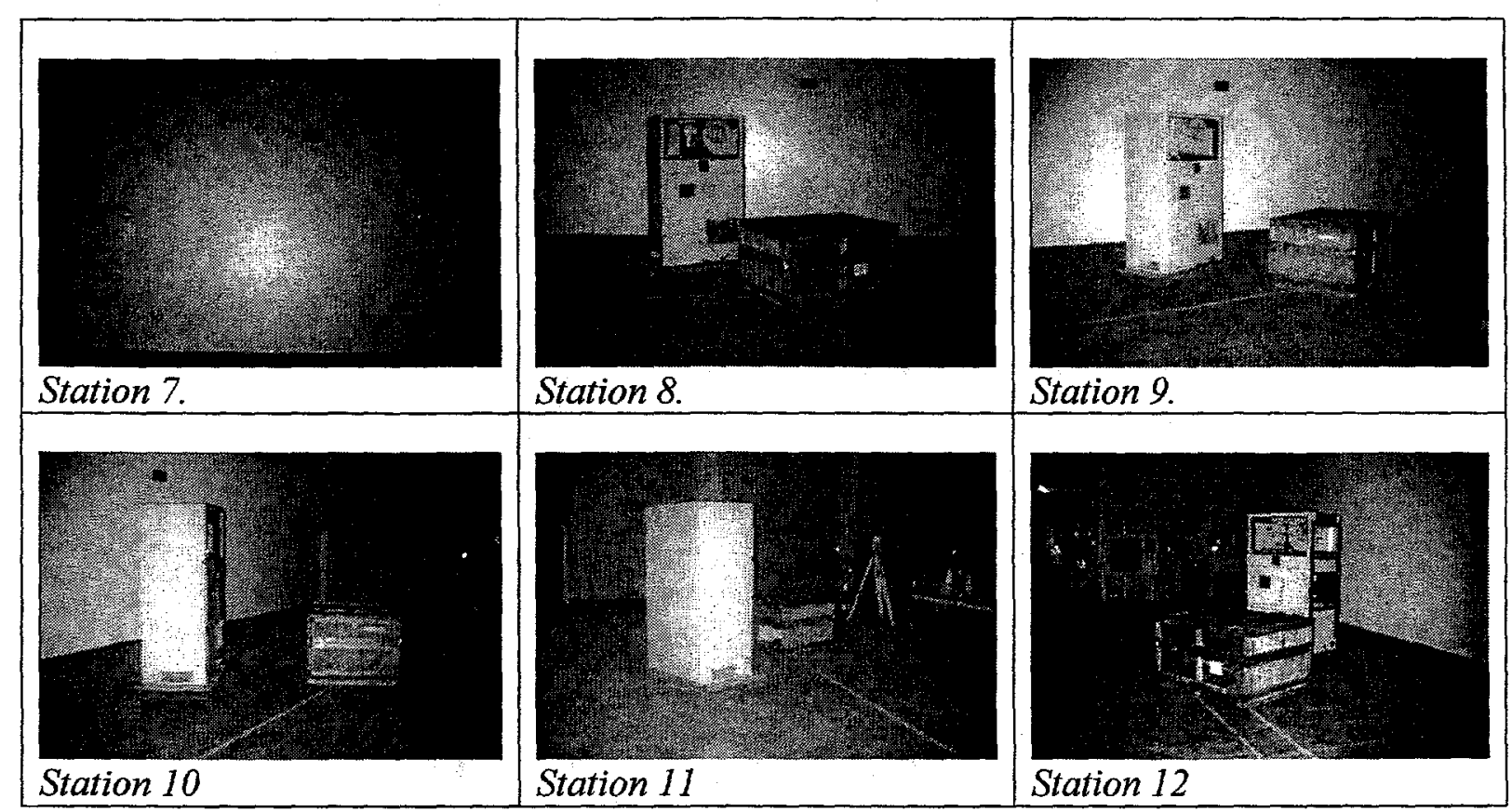

Table 3. Range images from each of six measurement stations after downsampling and adjustments.

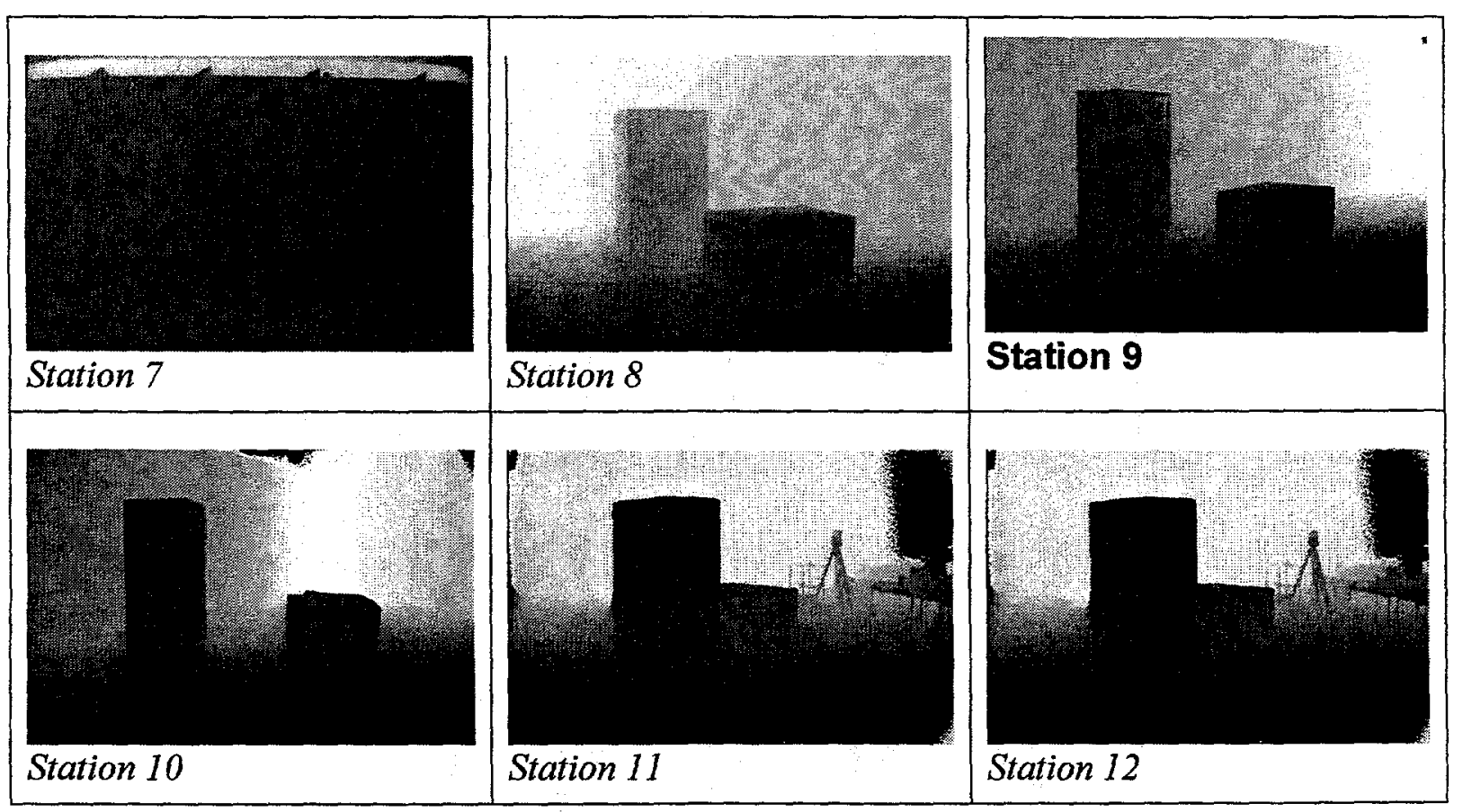




\section{Conclusion}

We have not included the field of view and other geometry of the range imager in this report because the specifications on the lens, image intensifier, faceplate, and other components are only a crude guide to actual imaging characteristics. We anticipate that users of these data will begin work by building a calibration of the imaging from correspondence of the imaged features with the survey measurements of these features. To date, we have had success with fitting a simple pinhole camera model to interpret these data.

Less usual than dealing with camera calibration is treating the systematic pattern of range and reflectance image errors produced by the image intensifier and its fiber optic faceplate coupling to the CCD. Figure 7 shows a window into the reflectance image from Station 10 (archive file photos/box_10_zoomed.jpg). The faceplate was manufactured by first arraying bundles of optical fiber, then fusing these bundles together. The residual structure of this process, especially the effects at the edges of the bundles, is clearly imprinted on the reflectance image. Systematic errors from the faceplate also appear in the range data, of course. Obtaining these measurements with a lower-resolution CCD would suppress the optical fiber patterns, of course. However, careful processing of the high-resolution data can also suppress these errors with less severe reduction in spatial resolution. Suppressing the fiber patterns by simultaneous consideration of multiple views of a scene probably demands even more modeling and processing power that we envision for proper interpretation of this data collection. 


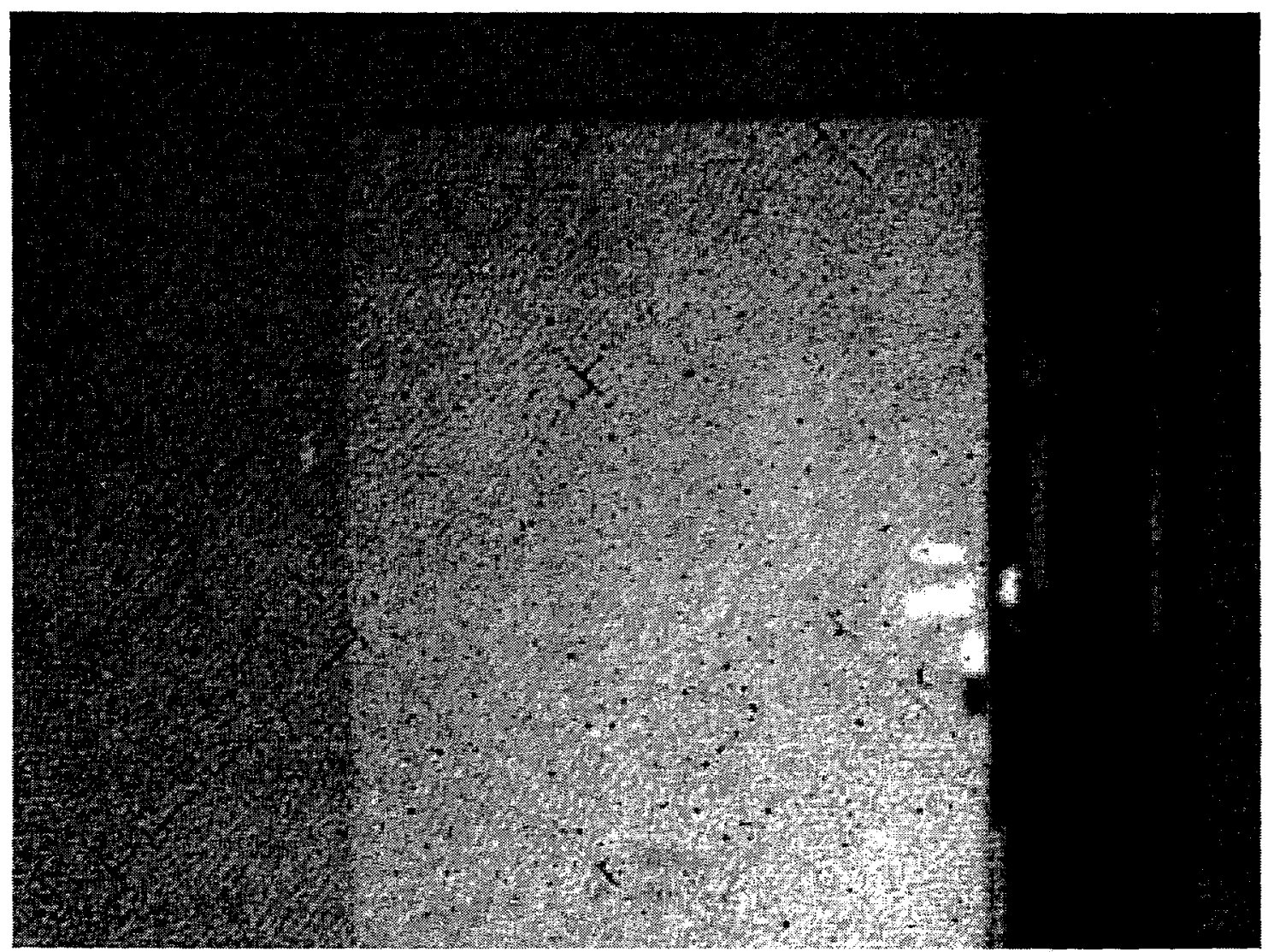

Figure 7. Diamond pattern of systematic error from the fiber optic faceplate is clear in this enhanced view of a portion of reflectance image taken from Station 10.

This report documents a data collection that recorded redundant range image data from multiple views of a simple scene, and recorded accurate survey measurements of the same scene. Collecting these data was a focus of the research project, Automated Geometric Model Builder Using Range Image Sensor Data, supported by Sandia's Laboratory-Directed Research and Development (LDRD) Program during fiscal years 1996, 1997, and 1998. The data described here are available from the authors on CDROM, or electronically over the Internet. Included in this data distribution are Computer-Aided Design (CAD) models we constructed from the survey measurements. The CAD models are compatible with the SolidWorks 98 Plus system, the modern Computer-Aided Design software system that is central to Sandia's DeskTop Engineering Project (DTEP). Integration of our measurements (as built) with the constructive geometry process of the $\mathrm{CAD}$ system (as designed) delivers on a vision of the research project. This report on our final data collection will also serve as a final report on the project. 


\section{References}

[1] Wild Instruments On Line: A Guide for connection of WILD instruments to computers via the Geo Serial Interface (GSI), Leica Heerbrugg AG, CH-9435 Heerbrugg (Switzerland), $11 / 1994$.

[2] Sackos, John T.; Bradley, Bart D.; Nellums, Bob; Diegert, Carl. Emerging versatility of a scannerless range imager. Proc. SPIE Vol. 2748, p. 47-60, Laser Radar Technology and Applications, Gary W. Kamerman; Ed. 6/1996.

[3] Diegert, Carl F.; Sackos, John T.; Nellums, Robert O. Building accurate geometric models from abundant range imaging information. Proc. SPIE Vol. 3065, p. 428-434, Laser Radar Technology and Applications II, Gary W. Kamerman; Ed. 8/1997.

[4] Sandia National Laboratories, Technology Transfer Opportunity - Scannerless Range Imaging System, Commerce Business Daily, 9/30/1994.

[5] Scott, M. W., Range Imaging Laser Radar, U.S. Patent 4,935,616, 6/19/1990.

[6] Anthes, J. P., P. Garcia, et al., Non-scanned LADAR Imaging and Applications, Applied Laser Radar Technology, Proceedings of SPIE, v. 1936, 1993.

[7] Garcia, P., J. P. Anthes, et al., Characterization of a Scannerless LADAR System, Applied Laser Radar Technology, Proceedings of SPIE, v. 1936, 1993.

[8] M. M. Lecavalier, et al., "Scannerless Range Imaging with a Square Wave," Guidance and Navigation - Applied Laser Radar Technology II, Proceedings of SPIE, 1995.

[9] Ken Frazier, Innovative Range Imager Sees How Targets Measure Up, Sandia Laboratory News, Vol. 46, No. 19, 9/16/1994.

[10] Cress, D. H. and M. M. Lecavalier, Fusion of LADAR with SAR for Precision Strike, Proceedings from the Eighth National Symposium on Sensor Fusion, 1995.

[11] Shepherd, O., L LePage, G. Wyntjes, T. Zehnpfenning, J. Sackos, R. Nellums, Counter Sniper 3-D Laser Radar Phase I STTR Final Technical Report, DARPA Contract No. DAAH01-96-C-R199, 9/16/1997.

[12] Fuchs. E., M. Bonin, J. Sackos, C. Smith, D. Goldstein, N. Rhymarchyk, Jr., Optical Sensors and Controls for Improved Basic Oxygen Furnace Operation: Lance-Based Temperature Measurement and Laser Radar Contouring, Presented at the 1997 AISE Annual Convention and Iron and Steel Exposition, Cleveland, OH, 9/29/1997 - 10/2/1997.

[13] Capt. M. Keltos, Demonstration of Imaging LADAR for Battle Damage Indication, Meeting of the IRIS Specialty Group on Active Systems, Albuquerque, NM, 3/1998. 
[14] Pletta. J. B., J.T. Sackos, An Advanced Unmanned Vehicle for Remote Applications, Sandia Report SAND98-0562, 3/1998.

[15] Fuchs. E., D. Hardesty, M. Bonin, J. Sackos, C. Smith, D. Goldstein, N. Rhymarchyk, Jr., Update of the BOF Lance-Based Temperature and Range/Contour Measurement.

Presented at the ISS Conference, Toronto Ontario, Canada, 3/22-25/1998.

[16] Sackos, John T.; Nellums, Robert O.; Lebien, Steve M.; Diegert, Carl F.; Grantham, Jeff W.; Monson, Todd. Low-cost high-resolution video-rate imaging optical radar. Proc. SPIE Vol. 3380, p. 327-342, Laser Radar Technology and Applications III, Gary W. Kamerman; Ed. 9/1998.

[17] Fuchs, E., M. Bonin, J. Sackos, C. Smith, D. Goldstein, N. Rhymarchyk, Jr. , Optical Sensors and Controls for Improved Basic Oxygen Furnace Operation. Lance-Based Temperature Measurement and Laser Radar Contouring, Reviewed and accepted for publication in Iron and Steel Engineer.

[18] Sackos, John T.; Bradley, Bart D.; Diegert, Carl F.; Ma, Paul W.; Gary, Charles. Scannerless terrain mapper. Proc. SPIE Vol. 2810, p. 144-153, Space Sciencecraft Control and Tracking in the New Millennium, E. Kane Casani; Mark A. Vander Does; Eds. 10/1996.

\section{Distribution.}

MS 0188

MS 9018

MS 0899

MS 0619

$10 \quad$ MS 0328

10 MS 1109
Donna Chavez (LDRD Office)

Central Technical Files, 8940-2

Technical Library, 4916

Review \& Approval Desk, 15102

For DOE/OSTI

John Sackos

Carl Diegert 